\title{
Performance evaluation of a plate type condenser for heat pump water heater
}

\author{
Hitoshi ASANO*, Kazuya HONDA*, Nobuhiro TAKEDA**, \\ Masaki KONDO** and Kazuhiro NISHIMURA** \\ *Department of Mechanical Engineering, Kobe University \\ 1-1 Rokkodai-cho, Nada-ku, Kobe 657-8501, Japan \\ E-mail: asano@mech.kobe-u.ac.jp \\ ${ }^{* \star}$ Noritz Corp. \\ 5 Minamifutami, Futami-cho, Akashi-shi, Hyogo 674-0093, Japan
}

Received 14 August 2014

\begin{abstract}
This study deals with an application of blazed plate heat exchangers to a condenser used in a heat pump water heater. The heat transfer performance was experimentally evaluated by using a pump driven two-phase flow loop in the operating condition for water heating at the environmental temperature. The effects of number of refrigerant paths and setting orientation, such as a vertical orientation with downward refrigerant flow or a horizontal orientation, were evaluated. HFC134a was used as the refrigerant. Superheated vapor was supplied to the condenser, and heated water, and then subcooled liquid was exhausted. Water was supplied to form a counter flow heat exchange. Three kinds of heat exchangers with different refrigerant paths of 6, 10, and 14 were used. Refrigerant temperatures at the exit of each path were measured by inserted thermocouples to evaluate the flow distribution. As a result, it was shown that vertical orientation produced higher heat transfer rate than the horizontal orientation. For the horizontal orientation, heat transfer rate decreased with an increase of refrigerant channels from 10 to 14 . The reason would be due to a maldistribution of the refrigerant. The deterioration in heat transfer performance for the horizontal orientation could be improved by the inclination of $15^{\circ}$ of the heat exchanger.
\end{abstract}

Key words : Plate heat exchanger, Condensation, Heat pump, Water heater, HFC-134a, Flow distribution

\section{Introduction}

Heat pump water heater is attracting attention for energy saving, because that can generate higher heating rate than the input energy. An electric heat pump water heater using $\mathrm{CO}_{2}$ as the refrigerant had been developed for residential use (Saikawa, 2001) and is marketed under the trade name of "Eco-cute" in Japan. Since $\mathrm{CO}_{2}$ flows as a supercritical condition in a heat exchanger for water heating, temperature gradient in the $\mathrm{CO}_{2}$ flow can reduce temperature difference in heat transfer when the temperature rise in the water flow is large. In this case, a long double tube heat exchanger is usually used as a gas cooler due to its high refrigerant pressure and large temperature rise of water. However, in the case when the inlet temperature of water is high, such as room heating operation, such large temperature gradient in the $\mathrm{CO}_{2}$ flow may cause a decrease in the coefficient of performance. On the other hand, it is unavoidable for an increase in generated hot water temperature to increase pressure of refrigerant. There will be a limitation on the operating pressure of $\mathrm{CO}_{2}$.

This study deals with a refrigerant with high boiling point. Since the refrigerant pressure is lower than $\mathrm{CO}_{2}$, plate heat exchanger is expected to be applied to the water heating heat exchanger for its compactness. The plate heat exchanger operates as a condenser for the water heater. Plate heat exchanger consisting of plates with herringbone corrugation has characteristics of high heat transfer coefficient and large pressure drop. Plate heat exchanger allows producing high heat transfer rate by increasing number of plates. Flow distribution into paths will strongly affect a heat transfer performance. When the refrigerant flow distribution is uneven, the heat transfer rate may decrease even if the number of paths is 
increased.

The effect of thermophysical properties on the coefficient of performance, COP, of a heat pump cycle had been evaluated by a cycle simulation based on thermodynamics. Examined refrigerants were $\mathrm{CO}_{2}$, propane, $\mathrm{HFC} 32$, and HFC134a. Operating conditions were selected to a standard condition for hot water supply in Japanese winter season. Then, the effect of an increase in the inlet temperature of water was evaluated for a room heating operation, for example. The calculation conditions are summarized in Table 1. The adiabatic efficiency of the compressor was considered in calculating the exhaust enthalpy from the compressor on the assumption that the compressor was a hermetic compressor. COP was defined as the enthalpy ratio of heating rate for hot water supply to compressor work. In the calculation for varied temperature of feed water, since the required heating rate will become lower with increasing the water temperature, the size of the heat exchanger is expected to be enough. Therefore, the terminal temperature difference at the inlet of water was set to be $0 \mathrm{~K}$.

Table 1 Calculation conditions in COP evaluation for various refrigerants.

\begin{tabular}{|c|c|c|c|}
\hline & & $\begin{array}{c}\text { Hot water supply } \\
\text { in winter }\end{array}$ & Room heating \\
\hline Refrigerant & Evaporation temperature & $2{ }^{\circ} \mathrm{C}$ & $2{ }^{\circ} \mathrm{C}$ \\
& Superheat at the evaporator exit & $7 \mathrm{~K}$ & $7 \mathrm{~K}$ \\
\hline Water & Feed water temperature & $9{ }^{\circ} \mathrm{C}$ & $40^{\circ} \mathrm{C}$ \\
& Output temperature & $90^{\circ} \mathrm{C}$ & $60^{\circ} \mathrm{C}$ \\
\hline Heat exchange & Terminal temperature difference at the inlet of water & $6 \mathrm{~K}$ & $0 \mathrm{~K}$ \\
for water heating & Temperature difference at the pinch point & $3 \mathrm{~K}$ & $3 \mathrm{~K}$ \\
\hline Compressor & Adiabatic efficiency & 0.7 & 0.7 \\
\hline
\end{tabular}

The $T$ - $h$ diagrams of the calculated cycles for the hot water supply using each refrigerant are plotted in Figs. 1 (a), (i) to (iv) with their saturation lines, respectively. Water temperature change in the heat exchange for each cycle is plotted by a blue solid line in each figure, respectively. The calculated results of COPs and refrigerant pressure in the water heater are shown in each figure. $\mathrm{CO}_{2}$ flows as a supercritical condition due to its low critical temperature, and the temperature gradient is quite large. Such large temperature gradient is effective to decrease the temperature difference in the heat exchange in the case when the temperature change of water is large. For the other three refrigerants, pressure in the water heater are lower than the critical pressure, so the temperature difference in heat exchange becomes larger in the condensation region.

The feed-water temperature will become higher in summer and the case when the heat pump cycle is operated for a room heating. Figures 1 (b), (i) to (iv) show $T$ - $h$ diagrams for a condition in a room heating operation. The $\mathrm{COP}$ of $\mathrm{CO}_{2}$ cycle becomes lower than the other cycles. For HFC32, the exhaust temperature from the compressor is higher than the other refrigerants due to its lower critical temperature. The difference in COP is a little among the three refrigerants except for $\mathrm{CO}_{2}$. The effect of the feed-water temperature on the COP and refrigerant pressure in the water heater is shown in Fig. 2. Water output temperature was set to $60^{\circ} \mathrm{C}$. Terminal temperature difference at the feed water side was set to 0 $\mathrm{K}$. The COP decreases with increasing the water feed temperature for either refrigerant. The amount of decrease in $\mathrm{COP}$ for $\mathrm{CO}_{2}$ is larger than the other refrigerant. It can be said that refrigerant with high critical point is effective for high temperature of feed water. It is important to clarify the condensing heat transfer characteristics.

Longo (2008, 2009, 2010), Longo and Zilio (2013), Longo, et al. (2014) reported the experimental results on condensation heat transfer in a brazed plate heat exchanger for several kinds of refrigerant, HFC134a (2008), hydro carbons (2010), HFC410A (2009), HFO1234yf (2013), and HFO1234ze(E) (2014). The plate heat exchanger consisting 10 plates had four refrigerant and 5 water paths. The plate configuration was $278.0 \mathrm{~mm}$ in length, $72.0 \mathrm{~mm}$ in width, 1.24 in enlargement factor of heat transfer surface, $65^{\circ}$ in corrugation angle, $2.0 \mathrm{~mm}$ in corrugation amplitude, and $8.0 \mathrm{~mm}$ in corrugation pitch. The test section was vertically placed with the refrigerant in downward flow and water in upward flow. Overall heat transfer coefficients were calculated for two sets of the inlet and exit refrigerant conditions, the inlet of nearly saturated vapor and the exit of nearly saturated liquid, and the inlet of superheated vapor and the exit of subcooled liquid. For example, it was shown for HFC134a that the overall heat transfer coefficient on the refrigerant side were independent from the refrigerant mass flux in the rage of the mass flux less than $20 \mathrm{~kg} /\left(\mathrm{m}^{2} \mathrm{~s}\right)$, and increased with increasing the mass flux in the range of the mass flux over $20 \mathrm{~kg} /\left(\mathrm{m}^{2} \mathrm{~s}\right)$. It was also reported that the difference in the tendency between the two refrigerant flow conditions was little. Although they constructed correlating equations on 
refrigerant heat transfer coefficient, the effect of flow distribution into paths were not discussed. Mancin, et al. (2011, 2012) reported the experimental results on condensing heat transfer in three types of brazed plate heat exchanger. In their experiments, the degree of inlet superheat was varied, and the exit condition was wet vapor.

In the practical conditions, since the superheated refrigerant exhausted from a compressor is cooled by heat exchange with cold water, the degree of superheat at the inlet and of subcooling at the exit will be higher than values in the previous studies. Especially, the subcooled liquid region may affect on the flow distribution due to its high pressure loss. In this study, experimental results on heat transfer performance of brazed plate heat exchangers for high degree of inlet superheat and exit subcooling of the refrigerant are shown. The effects of the number of paths, water flow rate, and the orientation, such as vertical or horizontal, on the heat transfer performance are discussed. Flow distribution of refrigerant was evaluated from the measured results of the exit temperature of refrigerant of each path.

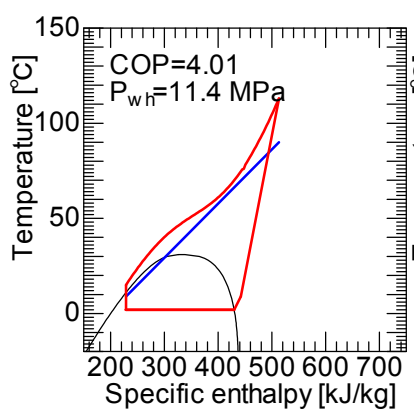

(i) $\mathrm{CO}_{2}$

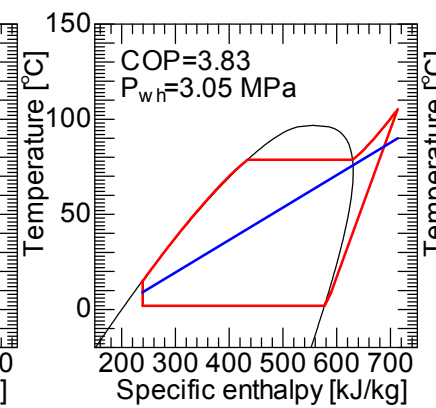

(ii) Propane

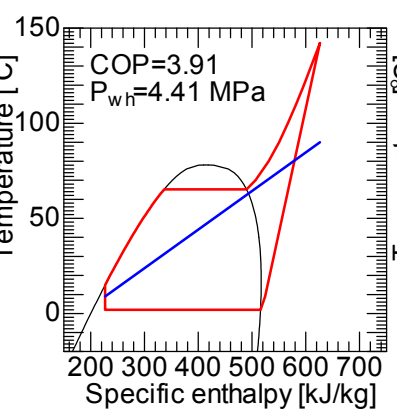

(iii) $\mathrm{HFC} 32$

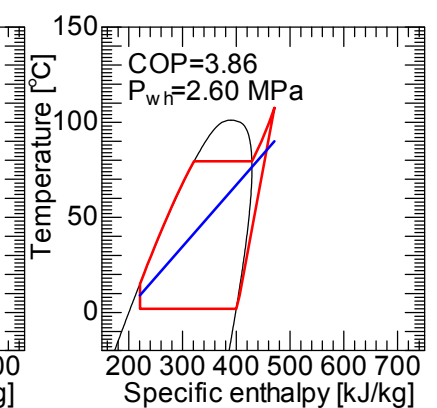

(iv) $\mathrm{HFC134a}$

(a) Case of a hot water supply in winter

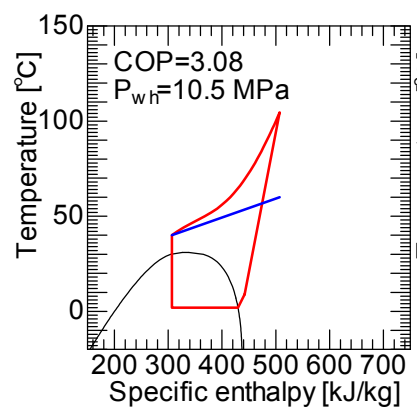

(i) $\mathrm{CO}_{2}$

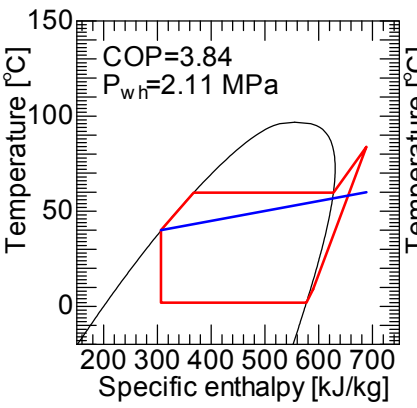

(ii) Propane

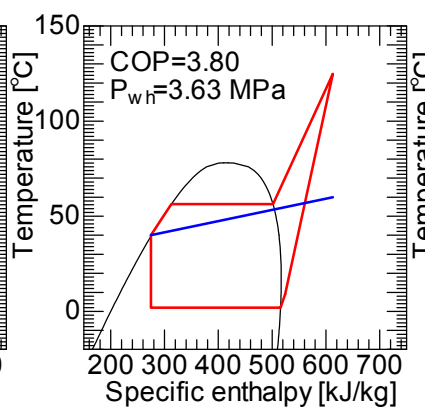

(iii) $\mathrm{HFC} 32$

(b) Case of a room heating

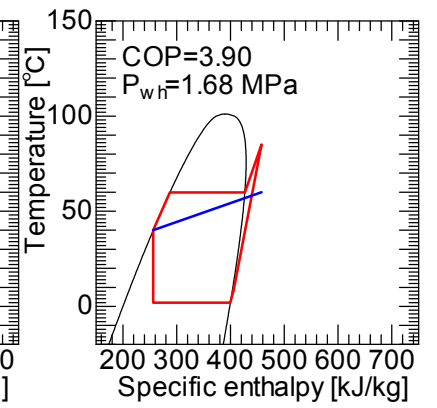

(iv) $\mathrm{HFC134a}$

Fig. 1 Temperature - specific enthalpy diagrams of heat pump cycle for several kinds of refrigerant. The red and blue lines show the change of state of refrigerant and water, respectively.

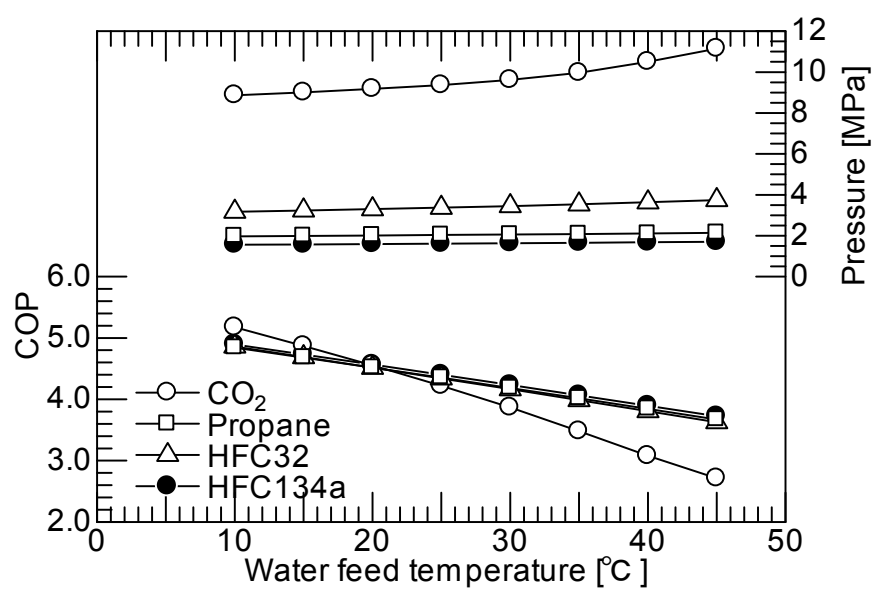

Fig. 2 Effect of water feed temperature on COP and refrigerant pressure in the water heater. 


\section{Experimental apparatus and methods}

Schematic diagram of the experimental apparatus is shown in Fig. 3. A two-phase flow loop in which the refrigerant was circulated by a mechanical gear pump was used for the measurements of heat transfer performance. HFC134a was used as the refrigerant. The flow rate was measured by a Coriolis mass flow meter. An accumulator connected to the loop as a branch at the upstream of the gear pump. The system pressure was maintained by the temperature of the accumulator. Liquid refrigerant vaporized in an evaporator and became superheated vapor through a superheater. The superheated vapor was supplied to the tested heat exchanger. The refrigerant was cooled to a subcooled liquid in the test section, and returned to the gear pump through a subcooler to keep an enough subcooling for the gear pump.

The plate configuration and channel cross-section are shown in Figs. 4. The plate heat exchangers were consisting of SUS thin sheets with the herringbone corrugation and the thickness of $0.3 \mathrm{~mm}$. The width of the sheet and the length between headers were $78.5 \mathrm{~mm}$ and $250 \mathrm{~mm}$, respectively. The enlargement factor, average cross-sectional area of each path, and average hydraulic equivalent diameter were $1.11,110 \mathrm{~mm}^{2}$, and $2.52 \mathrm{~mm}$, respectively. The tested brazed plate heat exchangers had 6,10,14 flow paths for refrigerant, and water has the same number of paths with the refrigerant. Figure 5 shows a schematic cross-section of plate heat exchanger with six refrigerant flow paths. Gray parts show the water channels. In order to evaluate heat transfer rate among the refrigerant paths, the refrigerant temperature at the exit of each refrigerant path was measured by the inserted sheathed thermocouple. The heat transfer experiments were carried out for a vertical and a horizontal orientation of the tested heat exchanger as shown in Figs. 6. For the vertical orientation, the refrigerant was supplied from the top to form a downward condensing flow. For the horizontal orientation, the inlet and outlet ports were mounted on the bottom side to prevent condensed liquid accumulating in the condenser. The water was supplied in the opposite direction to form a counter flow heat exchange. The temperatures were measured by K-type sheathed thermocouples with the resolution of $0.1 \mathrm{~K}$. The mass flow rate of refrigerant was measured by a Coriolis mass flowmeter with the measurement accuracy within $\pm 4.0 \%$ of the reading value, whose measurement range is up to 2.0 $\mathrm{kg} / \mathrm{min}$. The water flow rate was measured by an impeller type flow sensor with the measurement accuracy within $\pm 2.0 \%$ of the reading value. The pressure of refrigerant was measured at the inlet of the test section by a pressure transmitter with the measurement accuracy within $\pm 1.0 \%$ of the full scale, whose measurement range is up to $5.0 \mathrm{MPa}$. These measured data were collected in a data logger with the measurement frequency of $1 \mathrm{~Hz}$.

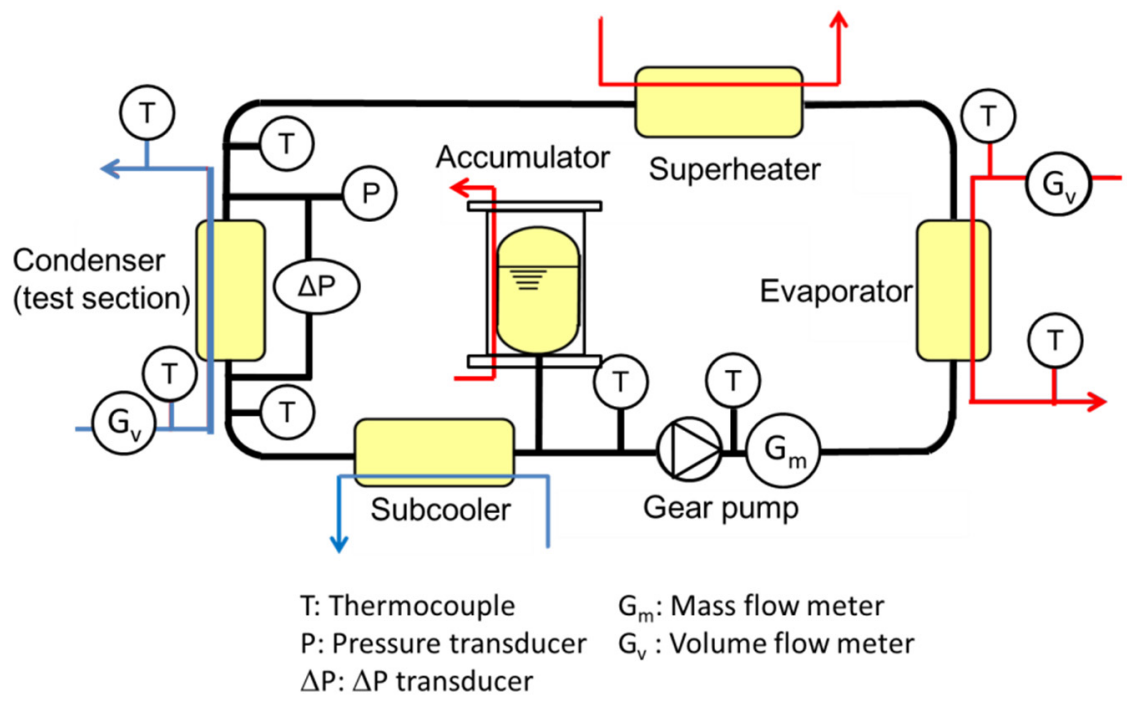

Fig. 3 Schematic diagram of experimental apparatus.

The experimental conditions are summarized in Table 2 . The refrigerant and water temperature at the inlet of the test section were constant at $83{ }^{\circ} \mathrm{C}$ and $17{ }^{\circ} \mathrm{C}$, respectively. The refrigerant mass flow rate was $1.2 \mathrm{~kg} / \mathrm{min}$, and the water mass flow rate was varied in the range of 0.9 to $1.4 \mathrm{~kg} / \mathrm{min}$. Pressure at the inlet of the heat exchanger was maintained at 1.86 $\mathrm{MPa}$. These experimental conditions were selected based on the standard operating condition of a water heater in midseason in Japan to supply hot water at $65^{\circ} \mathrm{C}$ with the heating capacity of $4.5 \mathrm{~kW}$ for the feed water at $17{ }^{\circ} \mathrm{C}$. The mean velocities and Reynolds numbers for each fluid are shown in Table 3. These values were calculated using the 
average cross-sectional area and average hydraulic equivalent diameter as shown above. For the refrigerant, the values for vapor and liquid single phase at the saturation condition are shown.
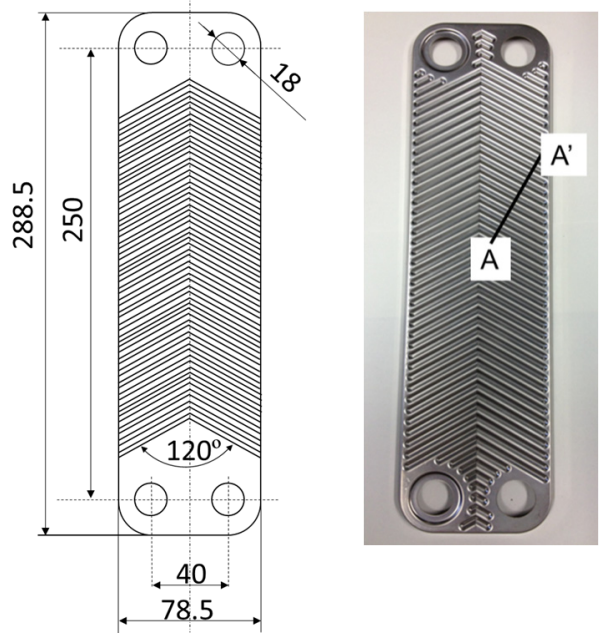

Cross-section A-A'

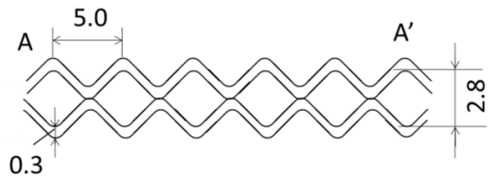

(unit : mm)

Fig. 4 Plate configuration.

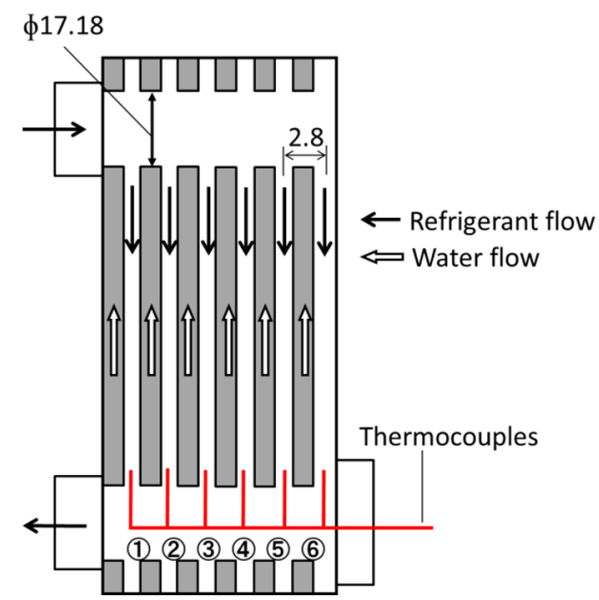

Fig. 5 Temperature measure points in the test section.

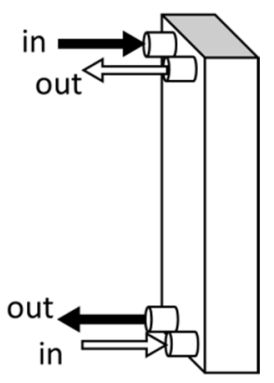

(a) Vertical orientation $\leftarrow$ Refrigerant flow $\Longleftarrow$ Water flow

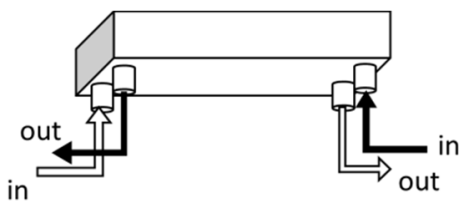

(b) Horizontal orientation

Fig. 6 orientation of the test section.

Table 2 Experimental conditions.

\begin{tabular}{|l|c|c|}
\hline & HFC134a & Water \\
\hline Inlet temperature & $83{ }^{\circ} \mathrm{C}$ & $17^{\circ} \mathrm{C}$ \\
\hline Mass flow rate & $1.2 \mathrm{~kg} / \mathrm{min}$ & 0.9 to $1.4 \mathrm{~kg} / \mathrm{min}$ \\
\hline Pressure & $1.86 \mathrm{MPa}$ & \\
Saturation temperature & $64.3{ }^{\circ} \mathrm{C}$ & \\
\hline
\end{tabular}

Table 3 Flow conditions of each fluid

\begin{tabular}{|c|c|c|c|c|c|c|c|c|c|c|c|}
\hline & \multicolumn{4}{|c|}{ HFC134a } & \multicolumn{7}{|c|}{ Water } \\
\hline & & \multirow{2}{*}{6 paths } & \multirow{2}{*}{10 paths } & \multirow{2}{*}{14 paths } & & \multicolumn{3}{|c|}{$0.9 \mathrm{~kg} / \mathrm{min}$} & \multicolumn{3}{|c|}{$1.4 \mathrm{~kg} / \mathrm{min}$} \\
\hline & & & & & & 6 paths & 10 paths & 14 paths & 6 paths & 10 paths & 14 paths \\
\hline \multirow[t]{2}{*}{ Velocity } & vapor $^{* 1}$ & 0.308 & 0.185 & 0.132 & $17^{\circ} \mathrm{C}$ & 0.0228 & 0.0137 & 0.00976 & 0.0354 & 0.0213 & 0.0152 \\
\hline & liquid $^{* 1}$ & 0.0295 & 0.0177 & 0.0126 & $70^{\circ} \mathrm{C}$ & 0.0233 & 0.0140 & 0.00997 & 0.0362 & 0.0217 & 0.0155 \\
\hline $\begin{array}{l}\text { Mass } \\
\text { flux }\end{array}$ & & 30.33 & 18.20 & 13.00 & $\begin{array}{l}17^{\circ} \mathbf{C} \\
70^{\circ} \mathbf{C}\end{array}$ & 22.75 & 13.65 & 9.749 & 35.39 & 21.23 & 15.17 \\
\hline Reynolds & vapor ${ }^{* 1}$ & 5483 & 3290 & 2350 & $17^{\circ} \mathrm{C}$ & 52.84 & 31.70 & 22.65 & 82.19 & 53.56 & 38.25 \\
\hline number & liquid $^{* 1}$ & 657.9 & 394.8 & 282.0 & $70^{\circ} \mathrm{C}$ & 141.6 & 84.94 & 60.67 & 220.2 & 132.1 & 94.38 \\
\hline
\end{tabular}

*1 Vapor or liquid means single phase flow. 


\section{Experimental results and discussion}

\subsection{Heat transfer rate}

Heat transfer rates for the vertical and horizontal orientation are plotted against the number of refrigerant paths, $n$, for the varied water mass flow rate $m_{\mathrm{w}}$ of 0.9 to $1.4 \mathrm{~kg} / \mathrm{min}$ in Figs. 7 (a) and (b), respectively. The heat transfer rate was calculated from the temperature elevation and heat capacity of the water flow.

Firstly, we discuss on the effect of the number of refrigerant paths, $n$, on the heat transfer performance with a constant flow rate of the refrigerant and water. The heat transfer rate $Q$ can be expressed by

$$
Q=K \cdot A \cdot \Delta T
$$

where $K$ is overall heat transfer coefficient, $\Delta T$ is the temperature difference between fluids, and $A$ is the heat transfer area. The heat transfer area, $A$, increases proportionally with increasing $n$. If it can be assumed that the heat transfer coefficient is dominated by the heat transfer coefficient of the water side, the effect of the water mass flux on the overall heat transfer coefficient will be a little, because the Reynolds number of the water flow is quite low as shown in Table 3. Therefore, the value of $K A$ is expected to increases proportionally with increasing $n$. On the other hand, the increase in heat transfer rate leads to the increase in the exit temperature of water and the decrease in the exit temperature of refrigerant. The fact leads to the increase in temperature effectiveness. The heat transfer rate will become saturated by the increase in temperature effectiveness.

In the results for the vertical orientation shown in Fig. 7(a), when the water mass flow rate $m_{\mathrm{w}}$ was the minimum at $0.90 \mathrm{~kg} / \mathrm{min}$, the effect of $n$ on the heat transfer rate was little. In this case, since the heat capacity of water was too small for the heat exchanger, the temperature effectiveness might become saturated. Therefore, it could not be expected to increase the heat transfer rate by increasing the heat transfer area. For the higher water flow rate, although the heat transfer rate might become saturated for the value of $n$ over 10 . For $m_{\mathrm{w}}=1.10$ and $1.31 \mathrm{~kg} / \mathrm{min}$, the heat transfer rate slightly decreased with increasing $n$ from 10 to 14 .

On the other hand, for the horizontal orientation shown in Fig. 7(b), the tendency was almost the same with the results for the vertical orientation. However, the heat transfer rates for $n=10$ became about $10 \%$ lower than those for the vertical orientation. Since the heat transfer coefficient of the water flow would not be affected by the orientation, the difference might be caused by the heat transfer performance of the refrigerant flow. For all cases except for the case with $0.90 \mathrm{~kg} / \mathrm{min}$, the heat transfer rate clearly decreased in spite of the increase of $n$ from 10 to 14 . The deterioration might be also caused by the heat transfer performance of the refrigerant flow, especially maldistribution might affect on the heat transfer performance.

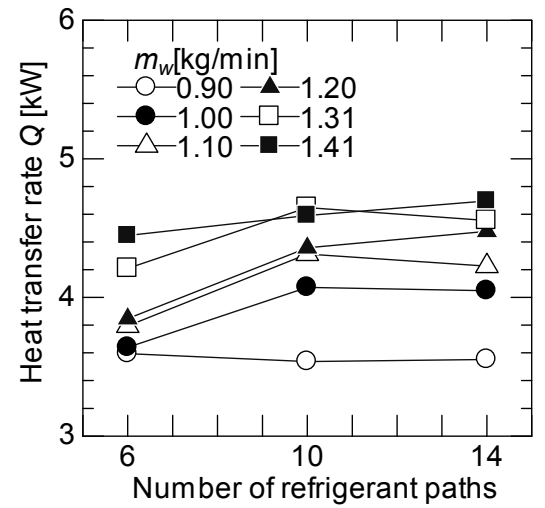

(a) Vertical orientation

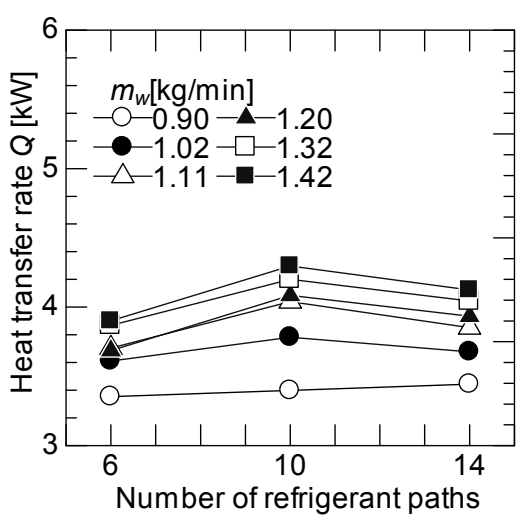

(b) Horizontal orientation

Fig. 7 Effect of number of refrigerant paths on heat transfer rate for varied water flow rates.

\subsection{Temperature difference at the pinch point}

Heat transfer rate can be expressed by the products of heat transfer coefficient, heat transfer area, and temperature difference as shown in Eq. 1. The reason that the heat transfer rate seemed to become saturated or decrease with increasing 
the number of refrigerant paths will be on the heat transfer performance or the temperature difference. In this section, temperature difference at the pinch point is discussed. Figure 8 shows an example of the temperature changes of refrigerant and water in the water heater plotted on a $T$ - $h$ diagram. The refrigerant temperature are plotted along an isobaric line at $1.86 \mathrm{MPa}$ without consideration of pressure change in the refrigerant flow due to the frictional pressure loss and momentum change with condensation. The refrigerant flows into the water heater as a superheated vapor at $83^{\circ} \mathrm{C}$ with the superheat degree of $18.7 \mathrm{~K}$, then condenses, and is discharged as a subcooled liquid. On the other hand, water at $17^{\circ} \mathrm{C}$ flows into the water heater, then is heated to $60^{\circ} \mathrm{C}$. In this case, at the point where superheated refrigerant becomes saturated vapor, the temperature difference between the refrigerant and water becomes the smallest. This point is referred to as pinch point shown by an arrow in Fig. 8. The heat transfer rate will become saturate when the temperature difference at the pinch point becomes close to 0 . From another perspective, smaller temperature difference at the pinch point means lower refrigerant pressure for the same water temperature condition, and will lead to an improvement in the COP.

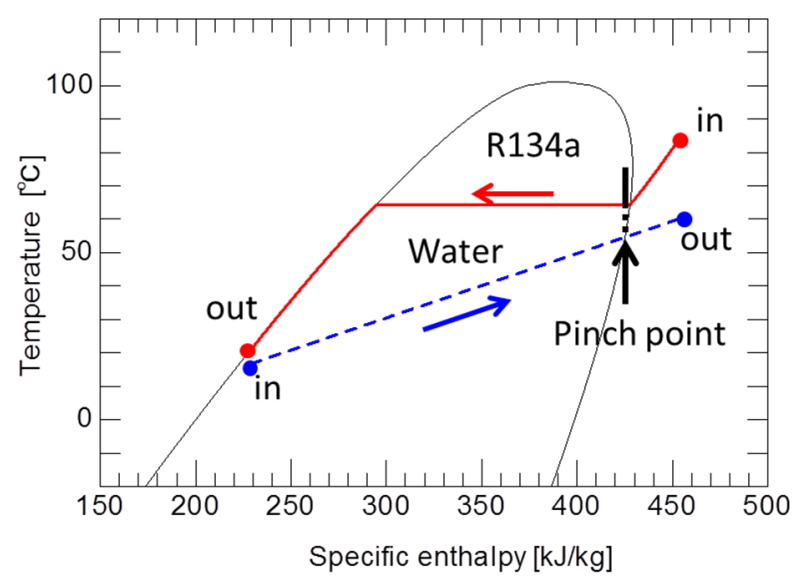

Fig. 8 Schematic diagram of temperature change of refrigerant and water in the water heater on a $T$ - $h$ diagram.

The temperature difference at the pinch point, $\Delta T[\mathrm{~K}]$, was calculated from measured terminal temperatures and heat transfer rate in the superheated vapor region. Obtained results of $\Delta T$ are plotted against water mass flow rate, $m_{\mathrm{w}}$ [kg/min], in Figs. 9 (a), (b). For the vertical orientation (Fig. 9 (a)), the $\Delta T$ for 10 paths became lower than 6 paths due to the increase of the heat transfer area. However, the $\Delta T$ for 14 paths was almost the same with 10 paths. It can be said that the increase in the heat transfer area was not effective to increase the heat transfer rate for this condition. In the range with the low water mass flow rate $\left(m_{\mathrm{w}}=0.9,1.0 \mathrm{~kg} / \mathrm{min}\right)$, the $\Delta T$ took negative values. The reason might be caused by nonuniform heat transfer rate among paths.

For the horizontal orientation (Fig. 9 (b)) at low water mass flow rate less than or equal to $1.0 \mathrm{~kg} / \mathrm{min}$, the $\Delta T$ decreased with increasing $n$ with the same tendency for the vertical orientation. However, for higher water mass flow rate over $1.0 \mathrm{~kg} / \mathrm{min}$, the $\Delta T$ increased in spite of the increase of $n$ from 10 to 14 paths. It could be estimated that the decrease was caused not by the temperature difference but by a deterioration in the heat transfer coefficient.

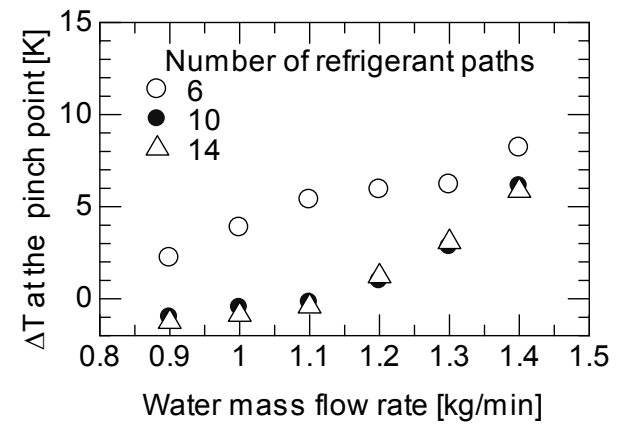

(a) Vertical orientation

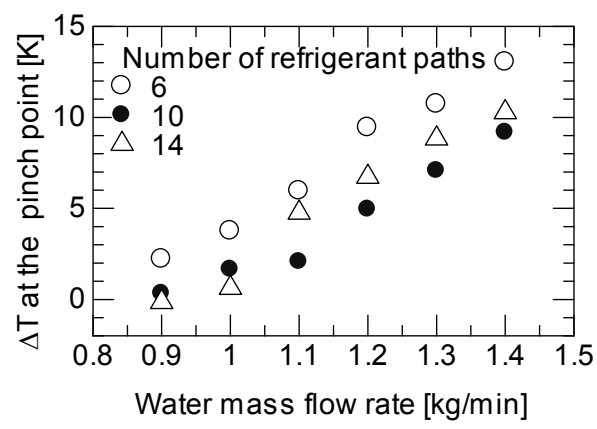

(b) Horizontal orientation

Fig. 9 Temperature difference between the refrigerant and water at the pinch point. 


\subsection{Evaluation of heat transfer rate in each path}

In order to estimate the heat transfer rate in each refrigerant path, the refrigerant temperature at the exit of each path were measured by using the inserted sheathed thermocouples. Measured results for the refrigerant paths of $6,10,14$ are shown in Figs. 10 (a) to (c), respectively. These values are time-averaged values for the given conditions of the inlet temperature and mass flow rate of refrigerant and water. The temperature fluctuation of refrigerant at the exit of each path became larger for the higher exit temperature. The results for the vertical and the horizontal orientation are shown in Figs. 10 (i) and (ii) for each number of paths, respectively. For the vertical orientation with 6 paths (Fig. 10 (a), (i)), a large variation in temperature distribution was observed in the condition with $m_{\mathrm{w}}$ of $0.91 \mathrm{~kg} / \mathrm{min}$. The refrigerant temperature at No. 4, 5, 6 was close to the saturation temperature according to the inlet pressure. The fact means that the heat transfer rate through the farther path from the inlet was not enough or the refrigerant flow rate through these paths was larger. The variation became smaller with increasing the water mass flow rate.

For the horizontal orientation with 6 paths (Fig. 10 (a), (ii)), while the exit temperatures decreased with increasing the water mass flow rate, the profile was kept. The refrigerant temperature was higher at the farther path from the inlet.

In each orientation, the same tendency in the temperature distribution was observed. The refrigerant flew into the inlet header as a vapor single-phase flow. Since the total pressure in the inlet header might be higher at the far end due to the inertia force, the refrigerant flow rate might be higher at the farther channel. On the other hand, the farthermost path was cooled by water from the one side wall as shown in Fig. 5. Such configuration might strengthen the variation.

For the vertical orientation with 10 paths (Fig. 10 (b), (i)), while the temperature variation was a little at the highest $m_{\mathrm{w}}$ of $1.40 \mathrm{~kg} / \mathrm{min}$, the refrigerant temperature became higher and the variation became larger with decreasing the water flow rate. For the $m_{\mathrm{w}}$ of $0.89 \mathrm{~kg} / \mathrm{min}$, all exit temperatures became close to the saturation temperature according to the inlet pressure. The shortage of heat transfer rate for the low $m_{\mathrm{w}}$ might be caused by the decrease in temperature difference at the pinch point as described in the section 4.2 .

For the horizontal orientation (Fig. 10 (b), (ii)), the temperature variation became larger with increasing the number of paths. The effect of water mass flow rate on the temperature distribution was a little at the nearest and farthermost path. From the results in which the variation for the horizontal orientation was worse than the vertical orientation, it could be estimated that the refrigerant flow distribution might be affected by gravity. Condensed liquid can be discharged from paths more easily in the vertical downward flow than the horizontal flow. The horizontal orientation requires higher pressure difference between the inlet and exit of the path to discharge condensed liquid. If there was a total pressure variation in the inlet header, the variation would become a trigger for a liquid stagnation. In this case, it was easy to stagnant liquid refrigerant at the nearest path from the inlet port.

For the vertical orientation with 14 paths (Fig. 10 (c), (i)), while the temperature variation was little for the higher $m_{\mathrm{w}}$ larger than $1.2 \mathrm{~kg} / \mathrm{min}$, the refrigerant temperature became higher with decreasing the water flow rate. When the $m_{\mathrm{w}}$ was $0.89 \mathrm{~kg} / \mathrm{min}$, all the exit temperatures became close to the saturation temperature. The effect of the orientation became larger with increasing $n$.

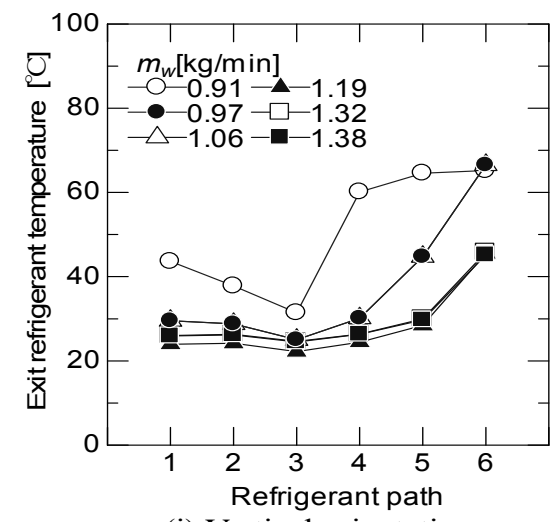

(i) Vertical orientation

(a) 6 refrigerant paths

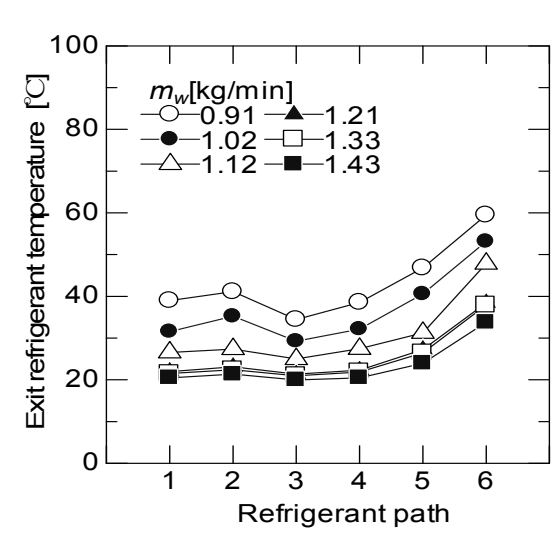

(ii) Horizontal orientation

Fig. 10 Refrigerant temperature distribution at the exit of each path to the header of the condenser. 


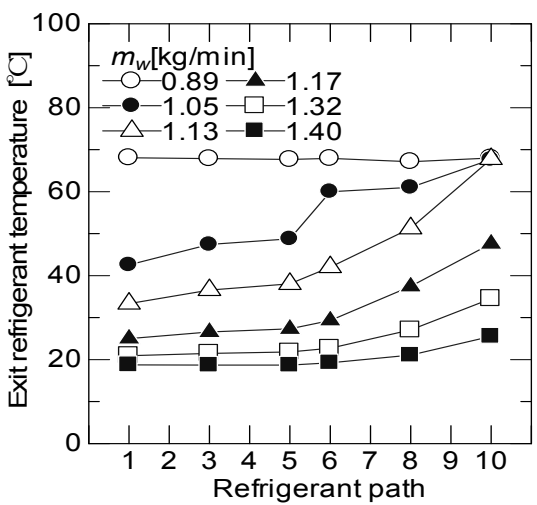

(i) Vertical orientation

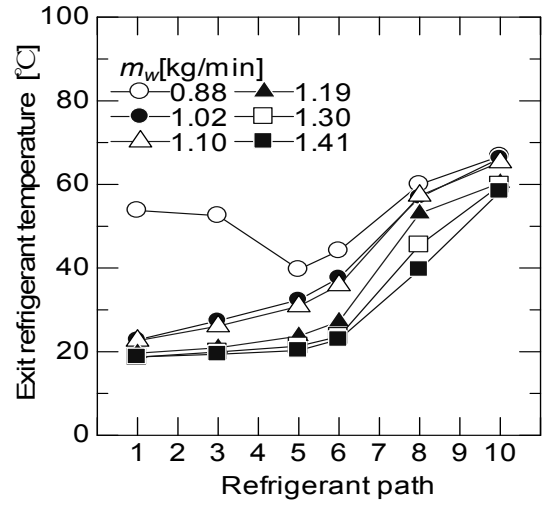

(ii) Horizontal orientation

(b) 10 refrigerant paths

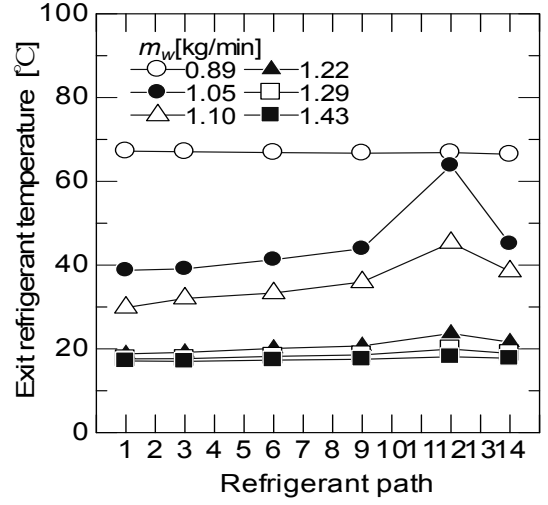

(i) Vertical orientation

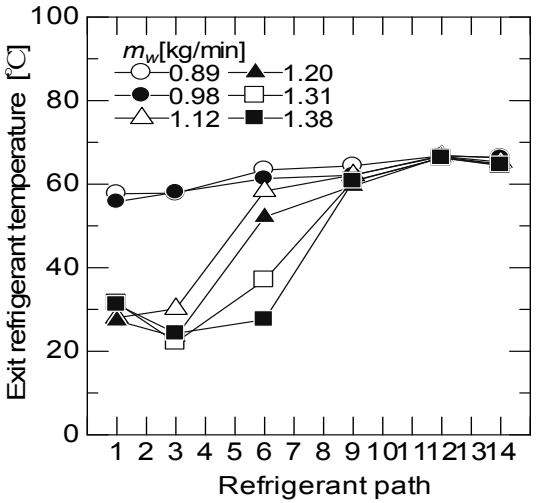

(ii) Horizontal orientation

(b) 14 refrigerant paths

Fig. 10 Refrigerant temperature distribution at the exit of each path to the header of the condenser.

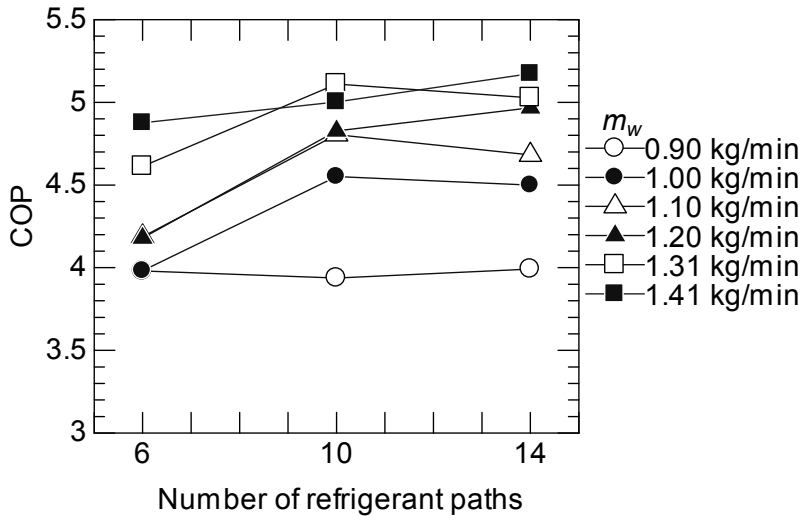

(a) Vertical orientation

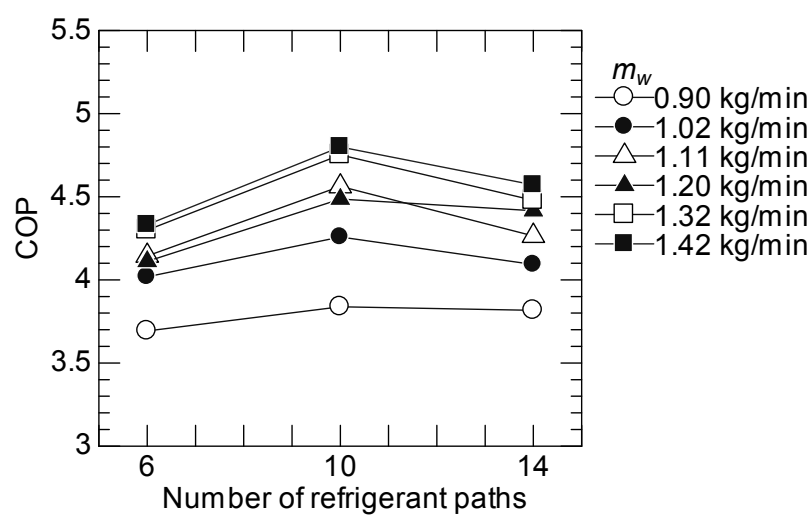

(b) Horizontal orientation

Fig. 11 Estimated values of COP.

\subsection{Estimation of the effect of heat transfer performance on COP}

In the design of heat pump cycle, it is important to evaluate the amount of decrease in COP caused by the decrease in the heat transfer performance. Giving the inlet condition of refrigerant for a compressor, the COP can be evaluated from the measured heat transfer rate. The compression work was estimated from the enthalpy difference between the inlet of the compressor and the inlet of the water heater. An inlet condition to a compressor was set to the evaporating temperature at $8{ }^{\circ} \mathrm{C}$ and superheat degree of $5 \mathrm{~K}$. Calculated COPs for the vertical and the horizontal operation are shown in Figs. 11 (a) and (b), respectively. In this case, the COP of up to 5.2 can be obtained by the heating rate of $4.6 \mathrm{~kW}$ using 
the plate heat exchanger with ten refrigerant paths in the vertical orientation. The decrease in the heating rate for the horizontal orientation is equivalent to the decrease of 0.4 in the COP.

\subsection{Improvement in the heat transfer performance by an inclination of the plate heat exchanger}

If condensed liquid in the horizontally placed water heater can be prevented from being stagnant by the inclination, the condensed liquid can be easily discharged from the exit header. The experimental results on the heat transfer rate are plotted in Fig. 12. The inclined angle is shown in the right figure of Fig. 12 as the parameter of $\theta$. The inclined angle, $\theta$, was set to $10^{\circ}$ and $15^{\circ}$. It could be seen from the results that the heat transfer rate could be improved by the inclination at $15^{\circ}$.
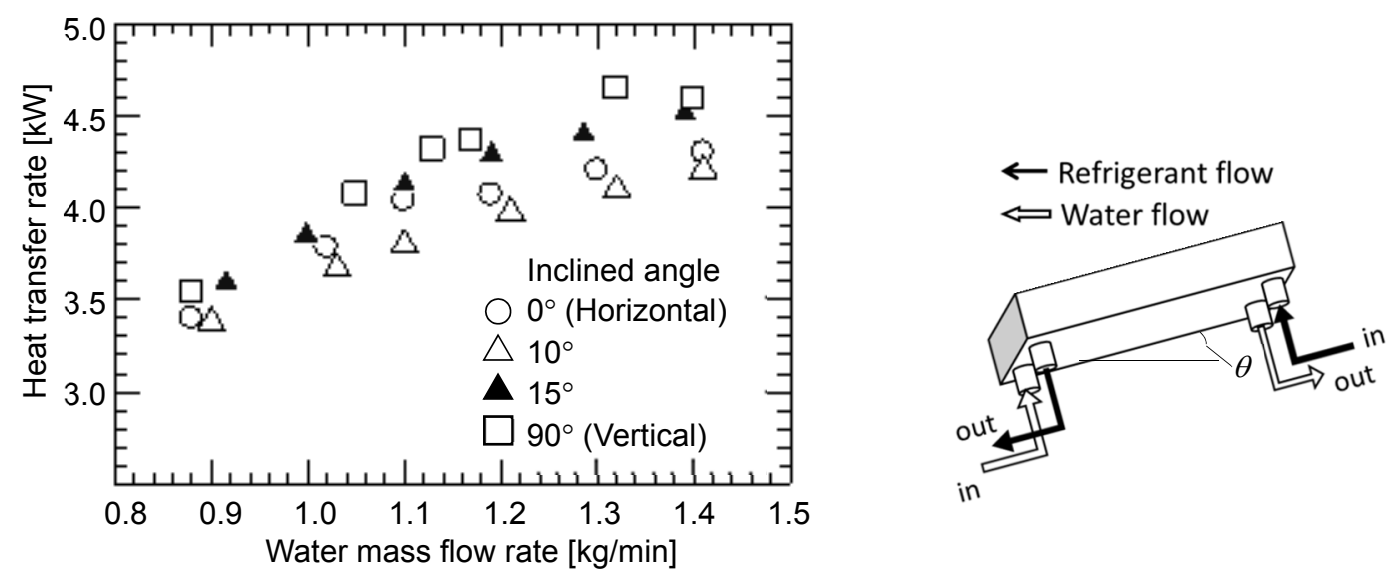

Fig. 12 The effect of the inclined angle of the water heater on the heat transfer performance for the horizontal orientation.

\section{Conclusions}

Heat transfer performance of brazed plate heat exchangers for a water heater in a heat pump hot water supply system was experimentally evaluated using HFC134a as the working fluid. The effects of the number of paths, 6,10 , and 14 paths, the setting operation, and the water mass flow rate, on the heat transfer performance were examined. The obtained results are summarized as the followings.

1. The vertical orientation with refrigerant downward flows could produce higher heat transfer rate than the horizontal orientation. Especially, the effect was remarkable for the number of refrigerant paths larger than 10.

2. It could be estimated from the measured temperature distribution of the refrigerant at the exit of each path that the decrease in heat transfer rate was caused by a maldistribution of refrigerant flow.

3. The heat transfer rate of the horizontal operation could be improved by the inclination at $15^{\circ}$.

\section{References}

Longo, G. A., Refrigerant R134a Condensation Heat Transfer and Pressure Drop inside a Small Brazed Plate Heat Exchanger, Int. J. of Refrigeration, Vol.31, (2008), pp. 780-789.

Longo, G. A., Heat Transfer and Pressure Drop during Hydrocarbon Refrigerant Condensation inside a Brazed Plate Heat Exchanger, Int. J. of Refrigeration, Vol.33, (2010), pp. 944-953.

Longo, G. A., R410A Condensation inside a commercial Brazed Plate Heat Exchanger, Experimental Thermal and Fluid Science, Vol. 33, (2009), 284-291

Longo, G. A., Zilio, C., Condensation of the Low GWP Refrigerant HFC1234yf inside a Brazed Plate Heat Exchanger, Int. J. of Refrigeration, Vol.36, (2013), pp. 612-621.

Longo, G. A., Zilio, C., Righetti, G., Brown, J. S., Condensation of the Low GWP Refrigerant HFO1234ze(E) inside a 
Brazed Plate Heat Exchanger, Int. J. of Refrigeration, Vol.38, (2014), pp. 250-259.

Mancin, S., Del Col, D., Rossertto, L., Condensation of Superheated Vapour of R410A and R407C inside Plate Heat Exchangers : Experimental results and simulation procedure, Int. J. of Refrigeration, Vol.35, (2011), pp. $2003-2013$.

Mancin, S., Del Col, D., Rossertto, L., R32 Partial Condensation inside a Brazed Plate Heat Exchanger, Int. J. of Refrigeration, Vol.36, (2012), pp. 601-611.

Saikawa, $\mathrm{M}$ and Hashimoto, K., Evaluation of Efficiency of $\mathrm{CO}_{2}$ Heat Pump Cycle for Hot Water Supply - Evaluation on Theoretical Efficiency and Characteristics -, Trans. of the JSRAE, Vol. 18, No. 3, (2001), pp. 217-223. (in Japanese) 